\title{
Comparative effectiveness of diet alone and diet plus metformin treatment on omentin levels in type 2 diabetes patients with nonalcoholic fatty liver disease: a prospective randomized trial
}

\section{IBRAHIM ARSLAN 1 \\ TURGAY ULAS ${ }^{2}$ \\ EMEL YIGIT KARAKAS ${ }^{1}$ \\ MEHMET DEMIR ${ }^{1}$ \\ MEHMET ALI EREN ${ }^{3}$ \\ AYSENUR TORUN ${ }^{3}$ \\ TEVFIK SABUNCU ${ }^{3}$ \\ ${ }^{1}$ Harran University, Faculty of Medicine Department of Internal Medicine, Sanliurfa/Turkey \\ ${ }^{2}$ Akdeniz University, Faculty of Medicine Department of Internal Medicine, Antalya/Turkey \\ ${ }^{3}$ Harran University School of Medicine \\ Department of Endocrinology, Sanliurfa/Turkey \\ Correspondence: \\ Turgay Ulas \\ E mail: turgayulas@yahoo.com}

Keywords: Nonalcoholic fatty liver disease, omentin type 2 diabetes mellitus
Received April 30, 2016.

Revised February 4, 2017.

Accepted February 9, 2017.

\begin{abstract}
Aim: The aim of this study was to compare the effectiveness of diet alone and diet plus metformin treatment on omentin levels in type 2 diabetes patients with nonalcoholic fatty liver disease.

Methods: Consecutively 88 patients who had hepatic steatosis with type2 DM were recruited for the study. For randomization, 28 patients who had exclusion criteria were excluded from the study. The remaining patients $(n=60)$ were randomized into two groups. Only diet therapy were given to Group $1(n=30)$ and metformin 2 gram/day plus diet were given to group $2(n=30)$ during 3 months. During the follow-up period 5 patients in group 1 and 1 patient in group 2 did not come for follow-up. Therefore we evaluated 25 patients in group 1 and 29 patients in group 2. Omentin levels were analyzed at admission and at the end of the study.
\end{abstract}

Results: There was a statistically significant difference in the values of body weight, body mass index, waist and hip circumference, body fat percentage (\%), and omentin in group 1; and in the values of body weight, BMI, waist and hip circumference, body fat percentage (\%), and omentin in group 2. Omentin levels were significantly decreased with the treatment in both groups $(5.37 \pm 1.31 \mathrm{ng} / \mathrm{ml} \mathrm{to} 4.00 \pm 1.46 \mathrm{ng} / \mathrm{ml}$ in group $1 ; 6.96$ $\pm 2.10 \mathrm{ng} / \mathrm{ml}$ to $3.92 \pm 0.89 \mathrm{ng} / \mathrm{ml}$ in group $2, p=0.001$ respectively). When compared the percentage of changes between two groups, it was found that the omentin value was more decreased in group $2(p=0.032)$.

Conclusions: Although diet and diet plus metformin treatment decreased the omentin levels, diet plus metformin treatment would be more beneficial in type 2 diabetes patients with nonalcoholic fatty liver disease.

\section{INTRODUCTION}

$\mathrm{N}$ onalcoholic fatty liver disease (NAFLD) can progress from simple steatosis to nonalcoholic steatohepatitis and liver cirrhosis. NAFLD is often associated with metabolic syndrome elements such as obesity, hyperlipidemia, type 2 diabetes, and insulin resistance (1-3). The key role of insulin resistance in the course of NAFLD has been shown in several studies. Eliminating of insulin resistance can prevent the development of NAFLD (4-6).

Metformin is an oral antidiabetics that shows the lowering effect on blood glucose by a reduction in hepatic glucose production and by an 
increase in insulin-dependent glucose uptake in skeletal muscle. It reduces the fatty acid oxidation in muscles and liver, and also shows positive effects on plasma lipid profile by reducing low-density lipoprotein cholesterol and very low density lipoprotein cholesterol (7). Omentin released from the visceral adipose tissue increases the activity of insulin in glucose metabolism and transport of glucose stimulated by insulin in subcutaneous adipocytes as well as in omental adipocytes. It was reported that serum omentin levels have decreased in obesity and insulin resistance $(8,9)$. Omentin gene expression has been decreased in obesity; decreased plasma omentin levels have been associated with increased obesity and insulin resistance (10).

Although omentin levels were found to be lower in patients with steatohepatitis, no research study has been performed to evaluate the effect of metformin therapy on omentin levels. Therefore, the purpose of this study is to examine the omentin levels in type 2 diabetic patients with hepatic steatosis and to compare the effects of diet and the diet plus metformin treatment on omentin levels.

\section{MATERIALS AND METHODS}

This prospective cohort study was conducted at the Harran University School of Medicine, Sanliurfa, Turkey. Prior to subject recruitment, the study protocol was reviewed and approved by the local ethics committee, in accordance with the ethical principles for human investigations, as outlined by the Second Declaration of Helsinki, and written informed consent was obtained from all the patients. Consecutively 88 patients who had hepatic steatosis with type-2 DM were recruited for the study.

The exclusion criteria were as follows: pregnancy; patients should be started insulin or insulin secretagogue; patients with contraindication to initiation of metformin; diabetic ketoacidosis; acute or chronic metabolic acidosis; renal failure; congestive heart failure; chronic liver disease; recent myocardial infarction; acute or chronic alcoholism; hypoxemia; and those against hypersensitivity to any component of the medication.

88 consecutive T2D patients with hepatic steatosis were recruited. Per protocol, 28 patients were excluded from the study. The remaining 60 patients were randomized into two groups. Group $1(\mathrm{n}=30)$ was assigned to diet alone; group $2(n=30)$ received diet + metformin for 3 months. 5 patients in group 1 and 1 patient in group 2 were lost to follow-up, accordingly, 25 patients in group 1 and 29 patients in group 2 were evaluated (Figure 1).

The diagnosis of diabetes mellitus was based on the American Diabetes Association 2012 criteria and on a previous history of diabetes (anti-diabetic medications usage), and NAFLD was diagnosed according to hepatobiliary ultrasound findings. Ultrasound findings for NAFLD were a diffuse hyperechoic echotexture (bright

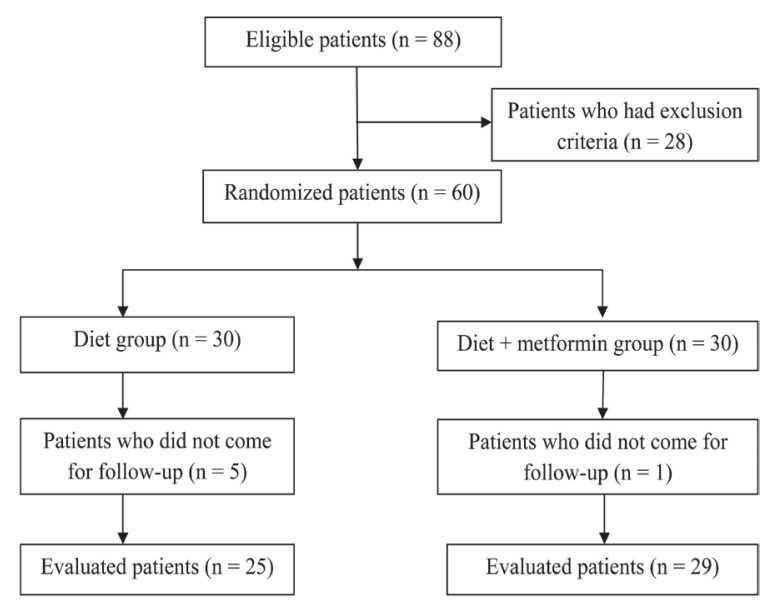

Figure 1. Consort diagram of the participants

liver), increased liver echotexture compared with the kidneys, vascular blurring, and deep attenuation $(11,12)$.

Height and weight were measured according to standard protocols. Body mass index (BMI) was calculated as the person's weight in kilograms divided by his or her height in meters squared $\left(\mathrm{kg} / \mathrm{m}^{2}\right)$. Body compositions were assessed with bioelectrical impedance analysis (BF 510, Omron Healthcare Co. Ltd., Kyoto, Japan). HOMAIR was used to evaluate insulin sensitivity of patients. HOMA-IR was calculated by the formula: [fasting serum glucose $(\mathrm{mg} / \mathrm{dl})$ x fasting serum insulin $(\mu \mathrm{U} / \mathrm{ml})] / 405$. Other biochemical analyses were determined using commercially available assay kits (Abbott, Abbott Park, USA) with an auto-analyzer (Abbott, Abbott Park, USA).

At the beginning and end of the study, $7 \mathrm{ml}$ of venous blood samples were taken from each patient to analyze omentin levels and were placed in biochemistry tubes. Venous blood samples were separated serums after centrifugation at $3500 \mathrm{rpm}$ for 10 minutes and serum samples were immediately stored at $-80^{\circ} \mathrm{C}$ until working time by putting into a special box. Serum omentin-1 levels were determined using an omentin-1 Enzyme Linked Immuno Sorbent Assay (ELISA; BioVendor Laboratorni medicina, Brno, Czech Republic). The results were formed in accordance with quality control serums and controls and were calculated according to the calibration curve. Omentin levels are referred in $\mathrm{ng} / \mathrm{mL}$.

All statistical analyses were performed using SPSS 20.0 for Windows (SPSS, Chicago, IL, USA). KolmogorovSmirnov tests were used to test the normality of the data distribution. The data were expressed as the mean and standard deviation. The chi-square test was used to compare the categorical variables between groups. Independent Sample T test and Mann-Whitney U tests were used for normally and nonnormally distributed continuous data, respectively. Paired t-test and Wilcoxon signed-rank tests were used to analyze changes in each group. A two-sided $p$ value $<0.05$ was considered to be statistically significant. 
Table 1. Demographic, anthropometric and laboratory features of the groups before treatment

\begin{tabular}{|c|c|c|c|}
\hline Parameter & $\begin{array}{l}\text { Diet group } \\
\quad \mathrm{N}=25\end{array}$ & $\begin{array}{l}\text { Diet plus metformin group } \\
\qquad \mathrm{N}=29\end{array}$ & $P$ value \\
\hline Age (years) & $38.36 \pm 10.14$ & $39.53 \pm 10.58$ & NS \\
\hline Gender $(\mathrm{M} / \mathrm{F})$ & $12 / 13$ & $15 / 14$ & NS \\
\hline Body Weight (kg) & $86.86 \pm 11.55$ & $90.94 \pm 15.82$ & 0.291 \\
\hline $\mathrm{BMI}\left(\mathrm{kg} / \mathrm{m}^{2}\right)$ & $33.08 \pm 4.86$ & $34.19 \pm 5.73$ & NS \\
\hline Waist circumference $(\mathrm{cm})$ & $107.48 \pm 9.34$ & $106.72 \pm 10.63$ & NS \\
\hline Hip circumference $(\mathrm{cm})$ & $111.80 \pm 10.25$ & $112.89 \pm 12.39$ & NS \\
\hline Body fat percentage (\%) & $38.36 \pm 10.14$ & $39.53 \pm 10.58$ & NS \\
\hline Glucose (mg / dl) & $132.48 \pm 35.93$ & $140.24 \pm 42.12$ & NS \\
\hline Creatinine (mg / dl) & $0.74 \pm 0.12$ & $0.76 \pm 0.22$ & NS \\
\hline $\operatorname{AST}(\mathrm{U} / \mathrm{L})$ & $28.40 \pm 25.18$ & $32.34 \pm 21.34$ & 0.027 \\
\hline $\operatorname{ALT}(\mathrm{U} / \mathrm{L})$ & $34.84 \pm 34.13$ & $45.68 \pm 38.25$ & 0.046 \\
\hline GGT (U / L) & $46.04 \pm 70.44$ & $47.06 \pm 28.74$ & NS \\
\hline Total Cholesterol (mg / dl) & $217.04 \pm 43.97$ & $198.68 \pm 39.81$ & NS \\
\hline LDL-Cholesterol (mg / dl) & $132.44 \pm 40.41$ & $114.37 \pm 32.89$ & 0.076 \\
\hline HDL-Cholesterol (mg / dl) & $41.64 \pm 9.12$ & $43.44 \pm 10.65$ & NS \\
\hline Triglycerides (mg / dl) & $211.28 \pm 107.75$ & $207.58 \pm 122.90$ & NS \\
\hline HbAlc (\%) & $6.36 \pm 0.67$ & $6.55 \pm 0.52$ & NS \\
\hline HOMA-IR & $6.54 \pm 4.78$ & $6.52 \pm 3.92$ & NS \\
\hline Omentin (ng/mL) & $5.37 \pm 1.31$ & $6.96 \pm 2.10$ & 0.002 \\
\hline
\end{tabular}

Variables were expressed as mean \pm standard deviations. NS: Not significant; BMI: Body Mass Index; AST: aspartate transaminase; ALT: alanine transaminase; GGT: gamma-glutamyl transferase; LDL-C: low-density lipoprotein cholesterol; HDL-C: high-density lipoprotein cholesterol; HbA1c: glycated haemoglobin; HOMA-IR: homeostasis model assessment of insulin resistance

Table 2. Anthropometric and laboratory values before and after treatment in Diet group

\begin{tabular}{|lccc|}
\hline Parameter & Before treatment & After treatment & P value \\
\hline Body Weight $(\mathrm{kg})$ & $86.86 \pm 11.55$ & $84.45 \pm 11.19$ & 0.001 \\
BMI $(\mathrm{kg} \mathrm{/} \mathrm{m})^{2}$ & $33.08 \pm 4.86$ & $32.15 \pm 5.12$ & 0.001 \\
Waist circumference $(\mathrm{cm})$ & $107.48 \pm 9.34$ & $105.08 \pm 9.01$ & 0.002 \\
Hip circumference $(\mathrm{cm})$ & $111.80 \pm 10.25$ & $109.08 \pm 9.90$ & 0.001 \\
Body fat percentage $(\%)$ & $38.36 \pm 10.14$ & $35.60 \pm 9.57$ & 0.008 \\
Glucose $(\mathrm{mg} / \mathrm{dl})$ & $132.48 \pm 35.93$ & $116.20 \pm 28.10$ & 0.008 \\
Total Cholesterol $(\mathrm{mg} / \mathrm{dl})$ & $204.96 \pm 45.82$ & $\mathrm{NS}$ \\
LDL-Cholesterol $(\mathrm{mg} / \mathrm{dl})$ & $128.28 \pm 45.26$ & $\mathrm{NS}$ \\
HDL-Cholesterol $(\mathrm{mg} / \mathrm{dl})$ & $217.04 \pm 43.97$ & $40.88 \pm 7.04$ & $\mathrm{NS}$ \\
Triglycerides $(\mathrm{mg} / \mathrm{dl})$ & $132.44 \pm 40.41$ & $177.40 \pm 78.27$ & $\mathrm{NS}$ \\
Hbalc $(\%)$ & $41.64 \pm 9.12$ & $6.15 \pm 0.53$ & 0.027 \\
HOMA-IR & $211.28 \pm 107.75$ & $3.49 \pm 3.37$ & $<0.001$ \\
Omentin $(\mathrm{ng} / \mathrm{ml})$ & $6.36 \pm 0.67$ & $4.00 \pm 1.46$ & 0.001 \\
\hline
\end{tabular}

Variables were expressed as mean \pm standard deviations. NS: Not significant; BMI: Body Mass Index; LDL-C: low-density lipoprotein cholesterol; HDL-C: high-density lipoprotein cholesterol; HbA1c: glycated haemoglobin; HOMA-IR: homeostasis model assessment of insulin resistance

\section{RESULTS}

The demographic, anthropometric and laboratory parameters of both groups before treatment are shown in Table 1 . There was no statistically significant difference in terms of clinical and demographic data between the two groups. When considered the effect of treatment; there was a statistically significant difference in the values of body weight, BMI, waist and hip circumference, body fat percentage (\%), HOMA-IR, HbAlc, glucose and omentin in group 1, and in the values of body weight,
BMI, waist and hip circumference, body fat percentage (\%), HOMA-IR, glucose, triglycerides, and omentin in group 2 (Table 2,3 ).

Omentin levels were significantly decreased with the treatment in both groups $(5.37 \pm 1.31 \mathrm{ng} / \mathrm{ml}$ to $4.00 \pm$ $1.46 \mathrm{ng} / \mathrm{ml}$ in group $1 ; 6.96 \pm 2.10 \mathrm{ng} / \mathrm{ml}$ to $3.92 \pm 0.89$ $\mathrm{ng} / \mathrm{ml}$ in group 2, $\mathrm{p}=0.001$ respectively) (Figure 2). When compared the percentage of change between two groups, it was found that the omentin value was more decreased in group $2(\mathrm{p}=0.032)$ (Figure 3$)$. 
Table 3: Anthropometric and laboratory values before and after treatment in Diet plus metformin group

\begin{tabular}{|c|c|c|c|}
\hline Parameter & Before treatment & After treatment & $P$ value \\
\hline Body Weight (kg) & $90.94 \pm 15.82$ & $87.79 \pm 15.37$ & $<0.001$ \\
\hline BMI $\left(\mathrm{kg} / \mathrm{m}^{2}\right)$ & $34.19 \pm 5.73$ & $32.99 \pm 5.70$ & $<0.001$ \\
\hline Waist circumference $(\mathrm{cm})$ & $106.72 \pm 10.63$ & $100.89 \pm 16.74$ & 0.036 \\
\hline Hip circumference $(\mathrm{cm})$ & $112.89 \pm 12.39$ & $109.41 \pm 12.40$ & $<0.001$ \\
\hline Body fat percentage (\%) & $39.53 \pm 10.58$ & $36.01 \pm 10.22$ & $<0.001$ \\
\hline Glucose (mg / dl) & $140.24 \pm 42.12$ & $123.51 \pm 32.17$ & 0.038 \\
\hline Total Cholesterol (mg / dl) & $198.68 \pm 39.81$ & $189.68 \pm 37.06$ & NS \\
\hline LDL-Cholesterol (mg / dl) & $114.37 \pm 32.89$ & $114.24 \pm 34.22$ & NS \\
\hline HDL-Cholesterol (mg / dl) & $43.44 \pm 10.65$ & $41.86 \pm 8.67$ & NS \\
\hline Triglycerides (mg / dl) & $207.58 \pm 122.90$ & $170.82 \pm 91.50$ & 0.034 \\
\hline Hbalc (\%) & $6.55 \pm 0.52$ & $6.24 \pm 0.24$ & NS \\
\hline HOMA-IR & $6.52 \pm 3.92$ & $4.00 \pm 3.80$ & 0.001 \\
\hline Omentin (ng / ml) & $6.96 \pm 2.10$ & $3.92 \pm 0.89$ & $<0.001$ \\
\hline
\end{tabular}

Variables were expressed as mean \pm standard deviations. NS: Not significant; BMI: Body Mass Index; LDL-C: low-density lipoprotein cholesterol; HDL-C: high-density lipoprotein cholesterol; HbAlc: glycated haemoglobin; HOMA-IR: homeostasis model assessment of insulin resistance

\section{DISCUSSION}

To the best of our knowledge, this is the first showing the effect of metformin therapy on body weight and the omentin level in type 2 diabetes mellitus patients with NAFLD.

Insulin resistance is the major factors behind the alterations of uptake, synthesis, degradation, and secretion of free fatty acids in the liver which leads to accumulation of lipids that cause the NAFLD (13). It has been shown that insulin resistance and fatty acid metabolism improved after significant weight loss $(14,15)$. Additionally, there are many studies reporting that losing weight provide improvement of histology $(16,17)$. Metformin is a first-line oral anti-hyperglycemic that improves insulin sensitivity in the liver and skeletal muscle (18). Metformin is not caused

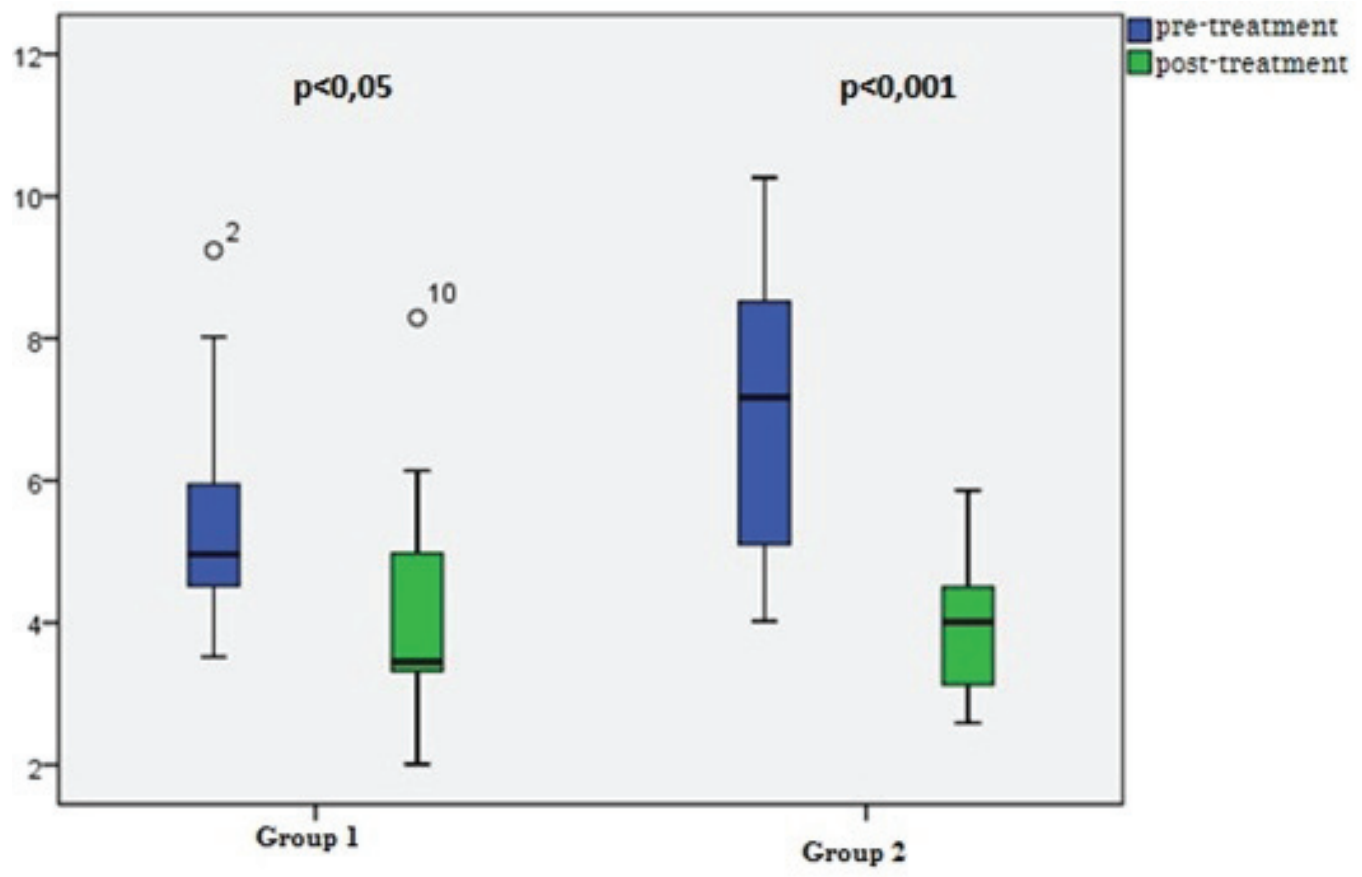

Figure 2: Graph demonstrating the pre-treatment and post-treatment omentin values both in groups 


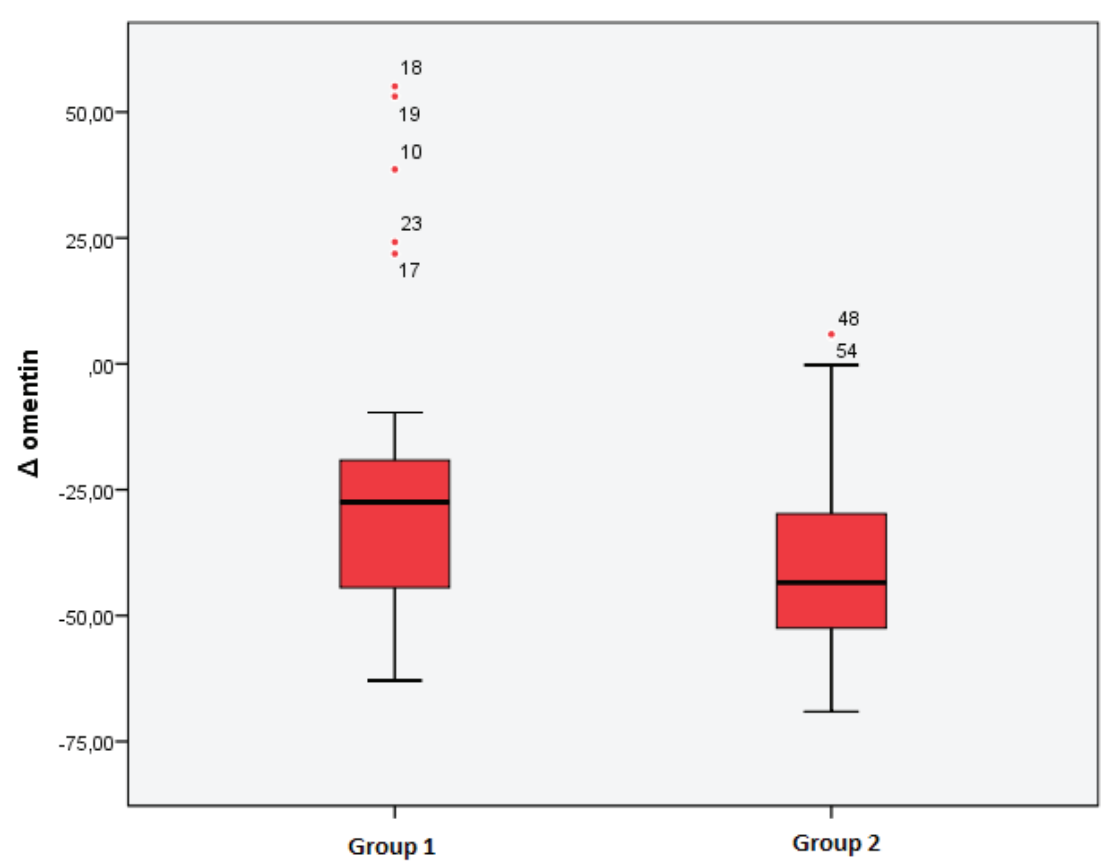

Figure 3: Graph demonstrating the percentage change of the omentin values both in two groups

weight gain and, in fact, it has been shown to induce modest weight loss (19-22). We detected that metformin did not provide additional impact to the weight-loss effect of diet therapy in diabetic patients with NAFLD.

It has been shown that omentin levels are increased in obese subjects after weight loss (23). Reduced omentin levels in patients with diabetes are also observed $(24,25)$. Interestingly, Yilmaz et al. showed that serum omentin levels are raised in patients with NAFLD, omentin levels are positively associated with hepatocyte ballooning-indicator of hepatocyte degeneration- independent of insulin resistance and some features of the metabolic syndrome (26). They also hypothesized that omentin might play a role in the development and progression of NAFLD. We detected that omentin levels are increased with loss of weight contrary to literature. NAFLD may be a confounder; so that, we suggest additional studies to identify reasons for this paradoxical increase as proposition of Yllmaz et al. (26).

Studies concluded that metformin did not improve findings of liver histology included steatosis, lobular inflammation, hepatocellular ballooning and fibrosis in NAFLD (27). Other studies demonstrated that metformin treatment decreased omentin levels in diabetes and polycystic ovary syndrome $(28,29)$. However, Esteghamati et al. found that both insulin sensitizers -metformin and pioglitazone- are decresed serum omentin concentrations in diabetic patients (30). In another study, Kim et al. found that metformin enhanced insulin sensitivity via independent mechanisms from phosphatidylinositol 3-kinase activity (31). Estagmati et al. hypothesized that after restored of insulin sensitivity, Akt signaling and its upstream mediators such as omentin might be suppressed.
Therefore, insulin sensitizers paradoxically inhibit the omentin by this negative feedback mechanism (32). Our similar results may be explained by this way.

When all of these data taken into account, metformin seem to not to provide additional benefits compared to weight loss. At present guidelines, metformin is not recommended as a primary treatment especially from the standpoint of nonalcoholic steatohepatitis (33). We can also say that it can be used in diabetic patients with NAFLD for other indications as recommended previously (34). Furthermore, the interactions of insulin sensitizers and NAFLD with omentin levels must be answered by further study.

The most important limitation of our study is the lack of enough patients and healthy control group. The comparison of omentin levels of diabetic patients with NAFLD and healthy individuals can provide new information to the literature. Another limitation of our study is the randomly higher omentin levels of diet plus metformin group at the beginning of study.

In conclusion, although the effects of diet and diet plus metformin treatment on BMI of our results are consistent with the literature, but their effects on the omentin level is inconsistent. The important of omentin in the course of NAFLD remain unknown. Altogether, our study adds to the current evidence suggesting that omentin may have unusual role in the diabetics with NAFLD. Therefore, these observations have to be replicated in larger, better randomized trials with comparison of healthy individuals.

Conflict of interest: None declared 


\section{REFERENCES}

1. SARGIN M, UYGUR-BAYRAMIÇLI O, SARGIN H, ORBAY E, YAYLA A. Association of nonalcoholic fatty liver disease with insulin resistance: is OGTT indicated in nonalcoholic fatty liver disease? J Clin Gastroenterol. 2003; 37(5): 399-402.

https://doi.org/10.1097/00004836-200311000-00010

2. ANGULO P, LINDOR KD. Non-alcoholic fatty liver disease. J Gastroenterol Hepatol. 2002; 17 Suppl: S186-90.

https://doi.org/10.1046/j.1440-1746.17.s1.10.x

3. SENATEŞ E, COLAK Y, YEŞIL A, COŞKUNPINAR E, SAHIN O, KAHRAMAN OT, ERKALMA ŞENATEŞ B, TUNCER I. Circulating resistin is elevated in patients with non-alcoholic fatty liver disease and is associated with steatosis, portal inflammation, insulin resistance and nonalcoholic steatohepatitis scores. Minerva Med. 2012; 103(5): 369-76.

4. HAQUE M, SANYAL AJ. The metabolic abnormalities associated with non-alcoholic fatty liver disease. Best Pract Res Clin Gastroenterol. 2002; 16(5): 709-31.

https://doi.org/10.1053/bega.2002.0325

5. ANGULO P. GI epidemiology: nonalcoholic fatty liver disease. Aliment Pharmacol Ther. 2007; 25(8): 883-9.

https://doi.org/10.1111/j.1365-2036.2007.03246.x

6. ANGULO P. Treatment of nonalcoholic fatty liver disease. Ann Hepatol. 2002; 1(1): 12-9.

7. SCARPELLO JH, HOWLETT HC. Metformin therapy and clinical uses. Diab Vasc Dis Res. 2008; 5(3): 157-67. https://doi.org/10.3132/dvdr.2008.027

8. TATEMOTO K, TAKAYAMA K, ZOU MX, KUMAKI I, ZHANG W, KUMANO K, FUJIMIYA M. The novel peptide apelin lowers blood pressure via a nitric oxide-dependent mechanism. Regul Pept. 2001; 99(2-3): 87-92.

https://doi.org/10.1016/S0167-0115(01)00236-1

9. YANG RZ, LEE MJ, HU H, PRAY J, WU HB, HANSEN BC, SHULDINER AR, FRIED SK, MCLENITHAN JC, GONG DW. Identification of omentin as a novel depot-specific adipokine in human adipose tissue: possible role in modulating insulin action. Am J Physiol Endocrinol Metab. 2006; 290(6): E1253-61. https://doi.org/10.1152/ajpendo.00572.2004

10. TAN BK, ADYA R, FARHATULLAH S, LEWANDOWSKI KC, O'HARE P, LEHNERT H, RANDEVA HS. Omentin-1, a novel adipokine, is decreased in overweight insulin-resistant women with polycystic ovary syndrome: ex vivo and in vivo regulation of omentin-1 by insulin and glucose. Diabetes. 2008; 57(4): 801-8. https://doi.org/10.2337/db07-0990

11. American Diabetes Association. Diagnosis and classification of diabetes mellitus. Diabetes Care. 2012; 35 Suppl 1: S64-71. https://doi.org/10.2337/dc12-s064

12. PALMENTIERI B, DE SIO I, LA MURA V, MASARONE M, VECCHIONE R, BRUNO S, TORELLA R, PERSICO M. The role of bright liver echo pattern on ultrasound B-mode examination in the diagnosis of liver steatosis. Dig Liver Dis. 2006; 38(7): 4859. https://doi.org/10.1016/j.dld.2006.03.021

13. SANYAL AJ, CAMPBELL-SARGENT C, MIRSHAHI F, RIZZO WB, CONTOS MJ, STERLING RK, LUKETIC VA, SHIFFMAN ML, CLORE JN. Nonalcoholic steatohepatitis: association of insulin resistance and mitochondrial abnormalities. Gastroenterology. 2001; 120(5): 1183-92. https://doi.org/10.1053/gast.2001.23256

14. MARRA F, LOTERSZTAJN S. Pathophysiology of NASH: perspectives for a targeted treatment. Curr Pharm Des. 2013; 19(29): 5250-69. https://doi.org/10.2174/13816128113199990344

15. THOMA C, DAY CP, TRENELL MI. Lifestyle interventions for the treatment of non-alcoholic fatty liver disease in adults: a systematic review. J Hepatol. 2012; 56(1): 255-66. https://doi.org/10.1016/j.jhep.2011.06.010
16. UENO T, SUGAWARA H, SUJAKU K, HASHIMOTO O, TSUJI R, TAMAKI S, TORIMURA T, INUZUKA S, SATA M, TANIKAWA K. Therapeutic effects of restricted diet and exercise in obese patients with fatty liver. J Hepatol. 1997; 27(1): 103-7. https://doi.org/10.1016/S0168-8278(97)80287-5

17. HARRISON SA, FINCKE C, HELINSKI D, TORGERSON S, HAYASHI P. A pilot study of orlistat treatment in obese, non-alcoholic steatohepatitis patients. Aliment Pharmacol Ther. 2004; 20(6): 623-8. https://doi.org/10.1111/j.1365-2036.2004.02153.x

18. SCARPELLO JH, HOWLETT HC. Metformin therapy and clinical uses. Diab Vasc Dis Res. 2008; 5(3): 157-67. https://doi.org/10.3132/dvdr.2008.027

19. INZUCCHI SE, BERGENSTAL RM, BUSE JB, DIAMANT M, FERRANNINI E, NAUCK M, PETERS AL, TSAPAS A, WENDER R, MATTHEWS DR; American Diabetes Association (ADA); European Association for the Study of Diabetes (EASD). Management of hyperglycemia in type 2 diabetes: a patient-centered approach: position statement of the American Diabetes Association (ADA) and the European Association for the Study of Diabetes (EASD). Diabetes Care. 2012; 35(6): 1364-79. doi: 10.2337/dc12-0413. Epub 2012 Apr 19. Review. Erratum in: Diabetes Care. 2013; 36(2): 490. https://doi.org/10.2337/dc12-0413

20. NOURY J, NANDEUIL A. Comparative three-month study of the efficacies of metformin and gliclazide in the treatment of NIDD. Diabete Metab. 1991; 17(1Pt 2): 209-12.

21. PRATLEY RE. The early treatment of type 2 diabetes. Am J Med. 2013; 126(9 Suppl 1): S2-9.

https://doi.org/10.1016/j.amjmed.2013.06.007

22. ROMANELLI RJ, CHUNG S, PU J, NIMBAL V, ZHAO B, PALANIAPPAN L. Comparative effectiveness of early versus delayed metformin in the treatment of type 2 diabetes. Diabetes Res Clin Pract. 2015 Jan 21. pii: S0168-8227(15)00046-7. doi: 10.1016/j. diabres.2014.12.019. https://doi.org/10.1016/j.diabres.2014.12.019

23. MORENO-NAVARRETE JM, CATALÁN V, ORTEGA F, GÓMEZ-AMBROSI J, RICART W, FRÜHBECK G, FERNÁNDEZ-REAL JM. Circulating omentin concentration increases after weight loss. Nutr Metab (Lond). 2010; 7: 27. https://doi.org/10.1186/1743-7075-7-27

24. TAN BK, ADYA R, RANDEVA HS. Omentin: a novel link between inflammation, diabesity, and cardiovascular disease. Trends Cardiovasc Med. 2010; 20(5): 143-8. https://doi.org/10.1016/j.tcm.2010.12.002

25. ZHOU JY, CHAN L, ZHOU SW. Omentin: linking metabolic syndrome and cardiovascular disease. Curr Vasc Pharmacol. 2014; 12(1): 136-43. https://doi.org/10.2174/1570161112999140217095038

26. YILMAZ Y, YONAL O, KURT R, ALAHDAB YO, EREN F, OZDOGAN O, CELIKEL CA, IMERYUZ N, KALAYCI C, AVSAR E. Serum levels of omentin, chemerin and adipsin in patients with biopsy-proven nonalcoholic fatty liver disease. Scand J Gastroenterol. 2011; 46(1): 91-7. https://doi.org/10.3109/00365521.2010.516452

27. MUSSO G, CASSADER M, ROSINA F, GAMBINO R. Impact of current treatments on liver disease, glucose metabolism and cardiovascular risk in non-alcoholic fatty liver disease (NAFLD): a systematic review and meta-analysis of randomized trials. Diabetologia. 2012; 55(4): 885-904. https://doi.org/10.1007/s00125-011-2446-4

28. YAN P, LI L, YANG M, LIU D, LIU H, BODEN G, YANG G. Effects of the long-acting human glucagon-like peptide-1 analog liraglutide on plasma omentin-1 levels in patients with type 2 diabetes mellitus. Diabetes Res Clin Pract. 2011; 92(3): 368-74. https://doi.org/10.1016/j.diabres.2011.02.030

29. TAN BK, ADYA R, FARHATULLAH S, CHEN J, LEHNERT H, RANDEVA HS. Metformin treatment may increase omentin-1 levels in women with polycystic ovary syndrome. Diabetes. 2010; 
59(12): 3023-31. doi: 10.2337/db10-0124. Erratum in: Diabetes. 2011; 60(7): 2008. https://doi.org/10.2337/db10-0124

30. ESTEGHAMATI A, NOSHAD S, RABIZADEH S, GHAVAMI M, ZANDIEH A, NAKHJAVANI M. Comparative effects of metformin and pioglitazone on omentin and leptin concentrations in patients with newly diagnosed diabetes: a randomized clinical trial. Regul Pept. 2013; 182: 1-6.

https://doi.org/10.1016/j.regpep.2012.12.005

31. KIM YB, CIARALDI TP, KONG A, KIM D, CHU N, MOHIDEEN P, MUDALIAR S, HENRY RR, KAHN BB. Troglitazone but not metformin restores insulin-stimulated phosphoinositide 3-kinase activity and increases p110beta protein levels in skeletal muscle of type 2 diabetic subjects. Diabetes. 2002; 51(2): 443-8. https://doi.org/10.2337/diabetes.51.2.443

32. KARLSSON HK, HÄLLSTEN K, BJÖRNHOLM M, TSUCHIDA H, CHIBALIN AV, VIRTANEN KA, HEINONEN OJ, LÖNNQVIST F, NUUTILA P, ZIERATH JR. Effects of metformin and rosiglitazone treatment on insulin signaling and glu- cose uptake in patients with newly diagnosed type 2 diabetes: a randomized controlled study. Diabetes. 2005; 54(5): 1459-67. https://doi.org/10.2337/diabetes.54.5.1459

33. CHALASANI N, YOUNOSSI Z, LAVINE JE, DIEHL AM, BRUNT EM, CUSI K, CHARLTON M, SANYAL AJ; American Gastroenterological Association; American Association for the Study of Liver Diseases; American College of Gastroenterologyh. The diagnosis and management of non-alcoholic fatty liver disease: practice guideline by the American Gastroenterological Association, American Association for the Study of Liver Diseases, and American College of Gastroenterology. Gastroenterology. 2012; 142(7): 1592-609. doi: 10.1053/j.gastro.2012.04.001. Erratum in: Gastroenterology. 2012; 143(2): 503.

https://doi.org/10.1053/j.gastro.2012.04.001

34. BARAN B, AKYÜZ F. Non-alcoholic fatty liver disease: what has changed in the treatment since the beginning? World J Gastroenterol. 2014; 20(39): 14219-29.

https://doi.org/10.3748/wjg.v20.i39.14219 